\title{
Unleashing the Power of Emotional Competency Development Program on Leaders' Self-Motivation
}

\author{
Halimah M. Yusof ${ }^{1}$ \\ ${ }^{1}$ Faculty of Management, Universiti Teknologi Malaysia, Johor, Malaysia \\ Correspondence: Halimah M. Yusof, Faculty of Management, Universiti Teknologi Malaysia, UTM Skudai, \\ 81310 Johor, Malaysia. Tel: 6-013-771-4239. E-mail: halimahmy@gmail.com
}

Received: October 23, 2015 Accepted: November 11, 2015 Online Published: April 19, 2016

doi:10.5539/ass.v12n5p64 URL: http://dx.doi.org/10.5539/ass.v12n5p64

\begin{abstract}
This study attempts to investigate the effects of the emotional competency development program on leaders' self-motivation. Eighty leaders at a non-profit agency in Malaysia were involved in an experimental/control group research design where the experimental group was given a nine-week emotional competency development program. Pre- and post-test were conducted to assess participants' self-motivation using the Motivation Sources Inventory. The findings indicate that the emotional competency development program does have an effect on increasing leaders' self-motivation. However, positive effects were only seen on intrinsic process, self-concept internal and goal internalization. Whereas, the instrumental and self-concept external does not produce any significant changes after the training. As a conclusion, this study has provided some empirical proof on the effectiveness of the EI training program on developing leaders' emotional intelligence and intrinsic motivation, which might contribute to the theoretical and methodological aspect of leadership development.
\end{abstract}

Keywords: motivation, leaders, emotional competency, leadership development

\section{Introduction}

Self-motivation (SM) is an important trait in leaders. Evidences from previous researches suggest that leader would benefit from having high self-motivational drives (Barbuto Jr., Fritz, \& Marx, 2002; Dulewicz \& Higgs, 2010). Motivation is known as an aspiration that produces certain behaviour. It is defined as an inner state that gives direction by encouraging appropriate behavioural reactions (McClelland, 1998). Motivation is a power from the inside that stimulates an act and controls the course of an act (Russell, 1971). Motivation is related to interest, relevance, expectancies and believes on the outcomes, decision to be involved, and persistence (Baker, 2011). Human motive often originated from the emotional sides of human. In which, the emotional competencies (EC) of an individual may direct their motives. This can be seen from the definition of the emotional competencies itself, which is "achieving one's goals through the ability to manage one's own feelings and emotions, to be sensitive to, and influence other key people, and to balance one's motives and drives with conscientious and ethical behaviour" (Higgs \& Dulewicz, 1999, p. 20). Hence, the possibility of developing leaders' self-motivation using an emotional competency development program should be explored. Emotional competency development program has often been seen as a great tool to increase leaders' EC (Cherniss, Grimm, \& Liautaud, 2010). Therefore, it is expected that the EC training may enhance leaders' self-motivation. Hence, the researcher believed that it is important to conduct a study to evaluate the effect of the emotional competency development program on leaders' self-motivation.

Another issue that intrigues the researcher to pursue this study is to investigate the links between emotion and motivation. Emotion is often associated with motivation, in fact, some links has been found between these two. For instance, Goleman (1995) theory of EI includes motivation as part of EC, while Mayer, Salovey, and Caruso (2000) believe motivation is somehow linked to EC, although rejecting the claims that it is a subset of EC. Thus, this study will use the possible links between EC and SM to investigate the possibility of using one training program to develop both EC and SM in leaders.

\subsection{Emotional Competency Development Program}

Emotional competency is "the capacity for recognizing our own feelings and those of others, for motivating ourselves and for managing emotions well in ourselves and in our relationships" (Goleman, 1998, p. 317). 
Emotional competency is very important in individual as it helps individual to manage their emotions throughout their life (Yusof, Kadir, \& Mahfar, 2014). Since the emergence of the emotional intelligence (EI) theories, researchers have put on more focus on the efforts to develop individual's EI. Many researchers found that EI could be developed through appropriate development program and would be very beneficial to leaders (Badea \& Pană, 2010; Cherniss, 2010; McEnrue, Groves, \& Shen, 2010). These claims have created a wide interest on EI related training programs. Previous studies have shown positive outcome from EI training. For instance, a quasi-experimental study that has been done by Jonker (2009) showed positive results on the participants' EI from the four-day EI training. The Bar-On Emotional Quotation Inventory (EQ-i) was used to measure the participants' EI before and after the training, in which, the post-test mean scores showed significant improvement in their EI. Another study that has been done by Dadehbeigi and Shirmohammadi (2010) to evaluate the effect of EI training program on participants' EI. In this study, 68 employees from an Iranian bank were given 16 hours of EI training and the Emotional Competence Inventory (ECI-2) was used to measure the participants' EI during the pre- and post-test. Their findings showed significant improvement only on the relationship management $(t=2.89, p<.05)$, while the other EI sub-factors showed no changes. However, there are yet studies done to evaluate the effects of emotional-related trainings on other human characteristics such as motivational attributes. Conducting a study to evaluate the effect of emotional related training programs on human motivation may open up new possibilities in human psychological development.

\subsection{Theories on Motivation}

There are many theories on motivation. Among the very first theory on motivation is the Maslow's hierarchy of needs. Maslow (1954) suggested a pyramid system known as needs hierarchy that consist five division of motives starting from the bottom-level needs that is a prerequisite to be fulfilled before moving on to the higher-level needs. Through this pyramid, it is believed that human should first fulfil their physiological needs such as food, water, and shelter. These needs are essential to keep us living. When these physiological needs are met, human will make the appropriate action to fulfil the next need, which is the safety needs. The safety needs includes financial and life security, which can be obtained through work, living in a safe environment and financial planning. Once the safety needs are met, human moves to the third stage in the pyramid, that is social needs. Social needs refer to love, acceptance and the sense of belonging. These needs could be fulfilled through bonding with family members, friends, and colleagues. The next stage is the esteem needs, in which, individual cultivate the own self-conception and worthiness. There are six principal of esteem needs, which are; the practice of living consciously, self-acceptance, self-responsibility, self-assertiveness, living purposefully and personal integrity (Branden, 1995). The social and esteem needs are essential for our psychological well-being. When the esteem needs is met, an individual will pursue the highest stage in the Maslow's pyramid, which is the self-actualization. In this stage, an individual will pursue their desire to become anything he or she aims to be, based on their ability, potential, capacities and talents. However, Maslow believed that this highest level of needs could only be achieved when all the previous needs have been fulfilled. However, Alderfer (1972) suggested that these needs can be classified into three categories, in which, he suggested that the physiological needs and the safety needs could be categorized as the existence needs. While the social needs and external esteem could be classified into the relatedness needs. Whereas, the internal esteem and self-actualization could be categorized as the growth needs. Contrary to the Maslow's theory, in his ERG theory, Alderfer believes that all these needs can be satisfied simultaneously, without the necessity to satisfy the lower-order needs first, before moving on the next needs.

The next influential theory on motivation is the McClelland's Needs theory. David C. McClelland (1961) suggested that human desires were influenced by the society their living in and from their own experience, particularly earlier in life. Through his theory, he proposed three categories of motivational needs, which are the Needs for Achievement (nAch), Needs for Power (nPow), and Needs for Affiliation (nAff). Individual with high nAch tends to work harder and focus more on achieving goal that they have set for themselves. They believed on setting high personal responsibility on their course of action. Meanwhile, those with high nPow yearn to be in the higher and influential position, in which, they could have control over others. They have high desire to influence others and lead a prestigious life. Whereas, those with high nAff, prefer to have a good relationship with those around them, and yearn to get others' approval. NAff individuals prefer to have a strong sense of belonging in their team or group and avoid conflicts. It is believed that all individuals have a combination of all these three motivators. However, each of us will have a higher tendency on either one of these motivators. This tendency will affect individual's choices in work and life. It will also have strong influence on individual's motivational attributes (Steers, Mowday, \& Shapiro, 2004).

Aside from the theories discussed above, Herzberg's (1966) hygiene theory is among the influential theories in 
motivation too. Herzberg's theory is also known as the two-factor theory. In this theory, the focus is more on the practical approach towards motivating employees. Herzberg believes that job satisfaction depends on two different factors, that is motivators (satisfiers) and hygiene factor (dissatisfiers). Motivator is the factors that could satisfy individuals in their working environment. Factors that act as the motivators are accomplishment, recognition, job security and career advancement. These factors, when met, will results in higher satisfaction and strong commitment in employees at the workplace. Whereas, hygiene factor, when unmet, would cause dissatisfaction in the workplace. Among the dissatisfiers are the salary, company policy, working environment, the quality of supervision and interpersonal relationships. The hygiene and motivators are distinct factors between each other. Therefore, to build a conducive working environment, special attention should be given to both factors. This is to ensure job satisfaction is kept to the highest among the workers.

All the above theories have contributed to the recent development in motivational studies. The recent findings are discussed below.

\subsubsection{Intrinsic and Extrinsic Motivation}

Over the years, researchers realized that motivation could be classified into two types, which are the intrinsic and extrinsic motivation (Deci \& Ryan, 1985). Intrinsic motivational behaviour is considered as a motivation to do certain tasks for the joy of doing the task itself. Intrinsically motivated individual do certain activity with no obligation or any apparent reward except for the feeling of accomplishment in doing the activity itself. Individuals with intrinsic motivation will challenge themselves by developing skills and capacities to fulfil their own sense of achievement. Therefore, when they do any activity, the motivation will come from their own self-determination, which is achieved by stimulating and persuading themselves by saying, "That's interesting, "I like to do" or "I enjoy doing that" (Reeve, 2014). Meanwhile, extrinsic motivation refers to doing a task due to the outside effect and environmental incentives such as food, money and recognition from others, or for fears of punishment if the task is not done. Individuals with high extrinsic motivation tend to do an activity in order to achieve the reward. Therefore, they will only be motivated if the task is followed by a reward or incentives, be it in the material, or in verbal form. Although, intrinsic motivation seems to be more important to human, and indeed it is, the extrinsic motivation is important too. While, the intrinsically motivated individuals tend to be more successful in life as they are more determined in doing tasks and in achieving their goals; the extrinsically motivated individuals can be persuaded to do tasks in which they have no interest at. Individuals will be obligated to go to work every day in order to earn money to buy food and meet their psychological needs. Extrinsic motivation could also lead to personal well-being. For example, the desire to lose weight and maintain a healthy body might increase individual's motivation to do exercises. Therefore, both the intrinsic and extrinsic motivation is important to individuals.

\subsection{Self-Motivation}

A strong motivational drive is required in a leader to achieve success (Howells, 2007). Hence, it is suggested that motivation is an important factor to be a successful leader (J. E. Barbuto, 2005). Furthermore, Goleman (2001) believes that lack of motivation in leaders may retard an organization's growth and success. Hong, Catano, and Liao (2011) added that those with motivation to lead (MTL) will be the most qualified person to hold the leadership position. His study showed that individual with high MTL were more charismatic as a leader compared to those with low MTL. He found that the intrinsically motivated individuals were more responsible in performing their duty as leaders.

In addition to that, leaders will face problems in motivating their employees if they themselves did not have adequate SM. Therefore, a self-motivated leader can assist in increasing the organization performances (Lord \& Brown, 2001). In fact, study shows that leaders' motivational attributes not only have an influence on their leadership style, but also have an effect on their followers' performances (Park \& Word, 2012). Thus, aside from $\mathrm{EC}, \mathrm{SM}$ is important for leaders too.

Through the literature, it has been seen that both motivation and emotion are equally important on leaders and these two was often links together (Christie, Jordan, Troth, \& Lawrence, 2007; Sloman, 1987; Zurbriggen \& Sturman, 2013). Emotion and motivation were seen to be interrelated due to the cause and effect relationship. For instance, individuals with SM possessed control of their own emotions while allowing that control to motivate themselves internally (McMullen, 2003). Additionally, Harmon (2000) claims that good use of EI in communication can increase motivation in the workplace. Supporting this, Elfenbein and Ambady (2002) found that effective use of the nonverbal communication through emotional understanding increased the motivational performance in the workplace. Furthermore, the relationship between EI and motivation has been found by Novarina and Unaradjan (2006) through their study that showed positive relationship between EI and work 
motivation $(r=.953, p<.01)$ of the employees at a company in Jakarta. Another study by Saad (2011) on 512 participants showed strong association between the EI and self-determined motivation $(r=.84, p<.05)$. Aside from that, Bissessar (2008) found high correlation between the EI and extrinsic motivation from the study on 145 college students.

Based on the relationship found between the emotion and motivation, it is believed that by increasing a person's EI, it may have the potential to improve leaders' motivation as well (Henry, 2011). However, although many studies have been done in the field of leadership and EI, there are yet studies been done to examine the effect of EI training on leaders SM level. Thus, this study is expected to provide some empirical data on the effects of the emotional competency development program on leaders' SM. This leads to the following hypothesis:

$\mathrm{H}_{0}$ : There are no positive changes in the leaders' self-motivation: (1) intrinsic process, (2) instrumental, (3) self-concept external, (4) self-concept internal, and (5) goal internalization after the leaders have attended the training.

\section{Methods}

The research design used for this study is the pre- and post-test with experimental and control group design. The participants' EC and SM were measured prior and after the intervention program. The age, gender, educational level and years of experience were used as control variables.

\subsection{Participants}

In the beginning, 97 leaders with at least two years of experience and supervised a minimum of two individuals from a non-profit agency in Malaysia were selected for this study through the non-probability convenience sampling methods. To reduce the sampling bias, the researchers chose a broad cross-section of individuals consisting males and females, with different age groups and education level. Therefore, the sample from this organization could be as representative as samples from other organization.

Participants were informed of the procedures and they are free to withdraw at any time. All participants gave their consent to participate in this study and their anonymity was protected. The participants received certificates of attendance for their participation in the study.

\subsection{Pre-test and Group Distribution}

All participants completed the pre-test to measure their EC and SM prior the intervention. The results of the pre-test are ranked and then divided into extremely high results, moderate results and extremely low results. Those with the results of extremely high scores and extremely low scores were exempted for further selection as these outliers would affect the outcome of this study (Kay, 2005). Therefore, eight respondents with extreme results were removed. After removing the outliers, only 89 leaders with medium scores were selected for further sampling and were divided homogenously into Experimental Group (EG) and Control Group (CG). In dividing the samples into two groups, all the participants with medium scores were numbered. Next, the researcher placed all the numbers in a bowl and selected 40 numbers randomly. Only these 40 numbers were incorporated into the EG. Then, with the remaining balance of participants, a random matching sampling were used to create a CG that has almost the similar demographic characteristics with the EG. The CG consisted of equal number of participants as CG, which is 40 participants. The remaining balances of participants were removed from the study as the number of participants required has been met. The use of this random matching sampling is to ensure the homogeneity of demographic characteristics for both groups. The experimental group had 14.90 $(\mathrm{SD}=11.52)$ mean years of work experience and $67 \%$ possessed at least a diploma. The mean age was 39.12 $(\mathrm{SD}=12.21)$ with $63 \%$ were female and $37 \%$ were male. The control group had $15.58(\mathrm{SD}=11.85)$ mean years of work experience and $79 \%$ possessed at least a diploma. The mean age was $40.92(\mathrm{SD}=12.35)$ with $58 \%$ were female and $42 \%$ were male. Levene's test for equality showed that both groups have comparable EC and SM scores.

\subsection{Self-Motivation Measures}

For the purpose of this study, SM refers to possessing control of one's emotions while allowing that control to motivate internally (McClelland, 1987; Reimers \& Barbuto, 2002). The Motivation Sources Inventory (MSI) was used to measure the self-motivation of the leader. J. E. Barbuto and Scholl (1998) developed the MSI based on the Leonard, Beauvais and Scholl's (1999) integrative typology. The MSI contains 30 items with five subscales and each subscale contains six items. MSI is a self-assessment measured using a six point Likert-type scale $(0=$ entirely disagree; 6 = entirely agree). The MSI measures five sources of motivation: (1) intrinsic process, (2) instrumental, (3) self-concept external, (4) self-concept internal, and (5) goal internalization. Intrinsic process (IP) refers to the motivation of doing tasks for the pleasure of it, instead for reward or external 
controls. It is equivalent with the Maslow's (1954) physiological needs theories. Instrumental (INS) refers to individuals that are motivated by certain tangible outcomes such as promotion and award. It is similar to the need for safety (Maslow, 1954) and need for power (David C. McClelland, 1987). Self-concept external (SCE) refers to individuals that are motivated by positive feedbacks and approval from others. They acted in a way to first, gain acceptance and then to gain status by trying to satisfy people around them. This source is similar to the need for love, affection and belonging (Maslow, 1954), and needs for affiliation (David C. McClelland, 1961). Whereas Self-concept internal (SCI) is a motivation sources produced internally by the individuals themselves based on their own value system (J. E. Barbuto, Jr., 2002). This source is similar to the need for esteem (Maslow, 1954) and need for achievement (David C. McClelland, 1961). Goal internalization (GI) refers to individual who are motivated by believing in the cause of a goal and will work hard towards the goal. It is similar to the Maslow's (1954) self-actualization. Sample items across the five scales include "I prefer to do things that are fun" (IP), "I like to be rewarded for extra responsibilities" (INS), "I am motivated when people make me feel appreciated" (SCE), "I prefer to do things that give me a sense of achievement" (SCI), "My motivation will be high when I believe in what I'm doing" (GI).

\subsection{Intervention}

The intervention used for this study is the emotional competency development program. Only the experimental group $(n=40)$ was given the training program. The program was started by providing some briefing on the procedure and schedule of the training program. During this session, participants were reminded not share or discuss any material or knowledge gained from the training with the control group to avoid threat to internal validity from the diffusion of the treatment and to maintain the experimental condition (Creswell, 2009).

A total of eighteen-hour session of emotional competency development training was given. This training was conducted in the form of workshops and divided into two-hour session each, for nine consecutive weeks with 7 days apart between each session. To ensure there is no experimenter bias during conducting the program, two independent observers attended the training sessions to evaluate the training process. The observers were colleges' professors whom had extensive experiences in conducting trainings. They filled in a training evaluation form with 10-points Likert scales to determine if the training was conducted in neutral manners, complied with the steps set out in the module content and the instructor was in no way tried to force positive results on the participants during each sessions.

The training module has been developed based on the current emotional-related training literatures. It focused on the development of the perception of emotion, managing own emotion, managing others emotion, utilization of emotion, self-regulation and internal motivation. Most of the targeted dimensions were based on the Goleman's model of EI.

\subsection{Post-test}

After the training has completed, the participants were retested for their SM using the MSI to measure the differences between the pre-test and post-test results.

\section{Analysis and Results}

The independent and paired sample t-test was used to determine the tested variables' mean scores difference between the pre- and post-test of the experimental group and control group. The data were analysed in SPSS v. 19 (Window 7). The effect size was compute using the Cohen's (1988) d-value to determine the significance of the result. The Cohen's $d$ greater than .2 is small, 0.5 is medium, and 0.8 is a large effect size.

The results of the paired sample t-test on the experimental group and control group with regard to the MSI presented in Table 1 showed mixed results.

The mean score for the total SM scores in experimental group showed significant differences with mean score increased by $0.21(t=-2.051, p<0.05)$, IP mean score increased by $0.34(t=-2.21, \mathrm{p}<0.05)$, SCI mean score increased by $0.34(t=-2.87, p<0.05)$, and GI mean score increased by $0.22(t=-2.65, \mathrm{p}<0.05)$. Medium effect size were found for all these three scores; IP $(d=0.64), \mathrm{SCI}(d=0.71)$ and GI $(d=0.71)$. However, the INS and SCE mean score did not show any significant differences. These results suggest that the $\mathrm{H}_{2}$ could only be partially supported as significant increase was seen only on IP, SCI and GI mean scores in the experimental group after the training. 
Table 1. Paired sample t-test for the pre-test and post-test scores of self-motivation in the experimental group and control group

\begin{tabular}{|c|c|c|c|c|c|c|c|c|}
\hline & \multicolumn{4}{|c|}{ Experimental Group $(n=40)$} & \multicolumn{4}{|c|}{ Control Group $(n=40)$} \\
\hline & $\begin{array}{c}\text { Pre-test Mean } \\
\text { (SD) }\end{array}$ & $\begin{array}{l}\text { Post-test Mean } \\
\text { (SD) }\end{array}$ & $\begin{array}{c}t \\
(\mathrm{df}=29)\end{array}$ & $\begin{array}{c}\text { Sig. } \\
\text { (2-tailed) }\end{array}$ & $\begin{array}{c}\text { Pre-test Mean } \\
\text { (SD) }\end{array}$ & $\begin{array}{c}\text { Post-test Mean } \\
\text { (SD) }\end{array}$ & $\begin{array}{c}t \\
(\mathrm{df}=29)\end{array}$ & $\begin{array}{c}\text { Sig. } \\
\text { (2-tailed) }\end{array}$ \\
\hline Total SM & $3.62(.36)$ & $3.83(.36)$ & -2.051 & $.049 * *$ & $3.60(.36)$ & $3.60(.33)$ & -.01 & $.990 * *$ \\
\hline IP & $3.42(.69)$ & $3.76(.48)$ & -2.21 & $.035^{* *}$ & $3.39(.68)$ & $3.39(.67)$ & .00 & $1.000 * *$ \\
\hline INS & $3.68(.65)$ & $3.73(.69)$ & -.29 & $.777 * *$ & $3.68(.60)$ & $3.64(.62)$ & .29 & $.775 * *$ \\
\hline SCE & $3.26(.65)$ & $3.34(.60)$ & -.45 & $.659 * *$ & $3.26(.61)$ & $3.22(.66)$ & .29 & $.774 * *$ \\
\hline $\mathrm{SCI}$ & $3.88(.48)$ & $4.22(.44)$ & -2.87 & $.008 * *$ & $3.83(.50)$ & $3.90(.46)$ & -.61 & $.544 * *$ \\
\hline GI & $3.84(.39)$ & $4.06(.25)$ & -2.65 & $.013 * *$ & $3.82(.40)$ & $3.84(.36)$ & -.20 & $.843 * *$ \\
\hline
\end{tabular}

Note: ${ }^{* *}$ Significant level $p<0.05$

\section{Discussion}

Through this study, the effect of 18-hour emotional competency development program conducted on leaders' SM showed mixed results. Researchers have found links between the emotional aspects of human being and their motivation (Christie et al., 2007; McClelland, 1987; Zurbriggen \& Sturman, 2013). This discovery might open the possibility that emotional related training could have an effect on individual's SM. Thus, $\mathrm{H}_{2}$ was tested to evaluate the effect of the emotional competency development program on leaders' SM. Findings showed mixed results for the effectiveness of the emotional competency development program in increasing the leaders' SM scores for the studied dimension. The findings seem to indicate that there were some positive effect from the training to the leaders' SM for the subscales of intrinsic process, self-concept internal and goal internalization. These three sources are categorized as the intrinsic motivation as it depends on internal sources of motivation. However, the findings fail to show significant improvement on leaders' external motivational sources of instrumental and self-concept external from the emotional competency development program.

The reason for the increased in the participants' intrinsic motivation might due to the increase in the participants' EC that in a way might has manage to tapped into the participants intrinsic motivational aspects. An explanation of this relationship could be linked to the Goleman's and Dulewiz and Higgs's model of EC that includes motivation as part of EC. Goleman (1995) subsumed motivation in the self-management clusters, while, Dulewicz and Higgs (2000) labelled motivation as drives in their EI model. Hence, it is not surprising when many other links were found between the EI component and motivation by other researchers. For instance, Goleman (1998) suggests that individual will find it easier to develop motivational competencies such as initiative and drives if they are capable of regulating their own emotion. Additionally, studies found that the achievement of needs (self-concept internal) is related to the regulation of emotion, while, the affiliation needs (self-concept external) is related to appraisal of emotion (Christie et al., 2007). Also, worth noting is that, individual intrinsic motivation were found to be affected by their self-worth and affective disposition (Ohtani \& Nakaya, 2011; Sutin \& Robins, 2005). This suggests that there is some linkage between emotion and motivation.

Looking at McClelland's (1987) work, he believed the linkage between motivation and emotion derives from certain incentive and affective reactions that we have been exposed to since infancy. For instance, when a child does good things or achieve something remarkable, their parents will hug them. This feeling of loving and affections somehow created a motivation for this kid to keep on performing better. In contrast, the fear of being rejected, or fear of failure will cause them to stay away from negative things. For instance, a child who has been scolded by the parents for doing something wrong would tend to avoid doing the things that will cause the same reaction. Indeed, positive affect were found to foster intrinsic motivation (Isen \& Reeve, 2005). Additionally, the links between emotions and motives has also seen in leaders, where EC competencies were found to be facilitating the inspirational motivation (Leban \& Zulauf, 2004). For instance, individuals with high intrinsic motivational attributes may not be motivated to do their tasks if they are feeling emotionally down. Positive emotion, on the other hand does foster the motivation to do tasks efficiently and increase the sense of responsibility in individuals (Isen \& Reeve, 2005). This cause and effect reaction between emotion and motivation might have explained the increase in part of participants' SM in this study. 
Additionally, the training modules that were focused on participant's own strength, abilities and guides given on increasing own optimism and self-worth (managing own emotion and utilization of emotion) during the training might have caused an increase in the participants self-esteem and positive affect, and thus increased their intrinsic motivation. Supporting this, it was found that SM could be developed by teaching individual to direct their behaviour towards their desired goals by using behavioural techniques such as self-monitoring, goal setting and self-reinforcement that is used during the training session in this study (Frayne \& Geringer, 2000).

The findings also highlight the difference of effect from the emotional competency development program on the two types of motivation, which is the extrinsic and the intrinsic motivation. Only the internal sources of motivation yielded significant results, while both of the external motivation sources failed to show any significant effect from the training. The possible explanation for the differences is that the increase in intrinsic motivation might have outgrown the extrinsic motivation in leaders. External motivation is the type of motivation that depends on outward or material stimuli to be motivated. Studies showed that the extrinsic motivation, which is the use of external stimuli may erode the intrinsic motivation in individuals (Christ, Emett, Summers, \& Wood, 2012; Ryan \& Deci, 2000). When intrinsic motivation is developed, the extrinsic motivation will be no longer be overcrowding the individuals' motivation. Thus, this might explains the increase in intrinsic motivation but not in the extrinsic motivation.

In summary, the findings from this study shows that the emotional competency development program has managed to develop the participants' SM. The increase in intrinsic motivation has masked down the extrinsic motivation, causing no significant changes in the extrinsic motivation.

\subsection{Implication}

There are few implications from this study; first, the used of pre-test and post-test experimental research with experimental and control group, and the use of real leaders in the workplace, instead of using students sample may provide a more valid empirical findings as compared to studies conducted to university's students.

Second, it is important to note that based on the researcher investigation, no other research has been found to examine the effect of emotional-related training on SM. Thus, this study might be the first to explore the possibility of developing leaders' SM using the emotional training. Although further research is needed, the emotional competency development program may have the possibility to develop leaders' intrinsic motivation. This promising finding might saves organizational training cost by providing only one comprehensive emotional competency development program instead of using two separate EI and motivation training to develop leaders' EC and SM.

In conclusion, this study might contribute new data and empirical proofs to respond to the lack of research and information in motivational development in leaders. The significance of this study is in the researcher's attempt to produce useful knowledge regarding the emotional competency development program on leaders and on how it will affect their motivational behaviour. It may have proved that emotional competency development program could be useful to yield favourable results such as developing leaders' SM.

\subsection{Limitation}

Although careful measures have been taken to ensure a strong study, there were still some limitations to this study. First, this experimental research is conducted in the real organization, using real leaders. Thus, the sample size used for this study is limited as only the minimum number of participants was allowed to be used by the organization. Using larger number of participants might have increased the statistical power of this study. Second, the use of the self-report measures might have affected the results of this study. These self-report measures are generally more lenient than the observers' measures. Using other type of measures such as the observer's measure might have yielded different results.

\subsection{Recommendation}

Although this study has been able to reach some conclusion about the effectiveness of the emotional competency development program in increasing leaders' intrinsic motivation, it also raises some concerns that could be further explored in future research. First, more information on the links between EC and SM should be gathered. Studies that are more comprehensive should be conducted to investigate which EC dimension affects which SM dimension and how each of these dimensions affects the others. Secondly, the future research could replicate this study by using different measurement instruments such as the observer's measures to see if the results would be the same as in this study. 


\section{Conclusion}

The results of this study suggests that emotional competency development program does produce significant improvement to the leaders' interestingly, only intrinsic motivation showed significant improvement, while the extrinsic motivation did not show any significant changes. This may have provided some insight on the relationship of the emotional and motivational aspects of human being. Furthermore, this study is the first study that simultaneously evaluates the effect of emotional competency development program on leaders' SM. Thus, it may provide not only the understanding on the effectiveness of the emotional competency development program on leaders' SM. This might provide some theoretical and practical benefits to the field of leadership development, human resources management and organizational psychology as a whole. Although further research is needed to gather more information on these areas, the researcher believed that this study has provided some contribution with valid empirical findings for the use of future studies.

\section{Acknowledgements}

This work was supported by the Ministry of Education (MOE), Malaysia and Universiti Teknlogi Malaysia (UTM) under vote No. Q.J130000.2729.01K51.

\section{References}

Alderfer, C. P. (1972). Existence, relatedness, and growth: Human needs in organizational settings.

Badea, L., \& Pană, N. A. (2010). The role of empathy in developing the leader's emotional intelligence. Theoretical \& Applied Economics, 17(2), 69-78.

Baker, S. C. (2011). Motivation, language identity and the L2 self. Journal of Multilingual and Multicultural Development, 32(2), 201-202.

Barbuto, J. E. (2005). Motivation and transactional, charismatic, and transformational leadership: A test of antecedents. Journal of Leadership \& Organizational Studies, 11(4), 26-40. http://dx.doi.org/10.1177/1071 79190501100403

Barbuto, J. E. Jr. (2002). Identifying the Sources of Motivation in the Post-Game Press Conference: An Exercise for Applying an Integrative Taxonomy of Motivation. The Journal of Behavioral and Applied Management, 4(1), 41-49.

Barbuto, J. E. Jr., Fritz, S., \& Marx, D. (2002). A field examination of two measures of work motivation as predictors of leaders' influence tactics. The Journal Of Social Psychology, 142(5), 601-616.

Barbuto, J. E., \& Scholl, R. W. (1998). Motivation sources inventory: Development and validation of new scales to measure an integrative taxonomy of motivation. Psychological Reports, 82(3), 1011-1022.

Bissessar, C. (2008). College students' emotional intelligence, extrinsic and intrinsic motivation as measurement of students' transformational leadership (Master Degree), University of Phoenix, Arizona, USA. Retrieved from https://vpn.utm.my/docview/304298429?accountid=41678

Branden, N. (1995). The six pillars of self-esteem. Bantam Dell Publishing Group.

Cherniss, C. (2010). Emotional Intelligence: New Insights and Further Clarifications. Industrial \& Organizational Psychology, 3(2), 183-191. http://dx.doi.org/10.1111/j.1754-9434.2010.01222.x

Cherniss, C., Grimm, L. G., \& Liautaud, J. P. (2010). Process-designed training: A new approach for helping leaders develop emotional and social competence. Journal of Management Development, 29(5), 413-431.

Christ, M. H., Emett, S. A., Summers, S. L., \& Wood, D. A. (2012). The Effects of Preventive and Detective Controls on Employee Performance and Motivation. Contemporary Accounting Research, 29(2), 432-452. http://dx.doi.org/10.1111/j.1911-3846.2011.01106.x

Christie, A., Jordan, P., Troth, A., \& Lawrence, S. (2007). Testing the links between emotional intelligence and motivation. Journal of Management \& Organization, 13(3), 212-226.

Cohen, J. (1988). Statistical power analysis for the behavioral sciences (2nd ed.). N.J.: Lawrence Erlbaum Associates.

Creswell, J. W. (2009). Research Design: Qualitative, Quantitative, and Mixed Methods Approaches. Sage Publication.

Dadehbeigi, M., \& Shirmohammadi, M. (2010). Training employees of a public Iranian bank on emotional intelligence competencies. Journal of European Industrial Training, 34(3), 211-225. 
Deci, E. L., \& Ryan, R. M. (1985). Intrinsic Motivation and Self-Determination in Human Behavior. N.Y.: Plenum Press.

Dulewicz, V., \& Higgs, M. (2000). Emotional intelligence-A review and evaluation study. Journal of Managerial Psychology, 15(4), 341-372. http://dx.doi.org/10.1108/02683940010330993

Dulewicz, V., \& Higgs, M. (2010). Leadership at the top: the need for emotional intelligence in organizations. The International Journal of Organizational Analysis, 11(3), 193-210. http://dx.doi.org/10.1108/eb028971

Elfenbein, H. A., \& Ambady, N. (2002). Predicting workplace outcomes from the ability to eavesdrop on feeling. Journal of Applied Psychology, 87(5), 963-971.

Frayne, C. A., \& Geringer, J. M. (2000). Self-management training for improving job performance: A field experiment involving salespeople. Journal of Applied Psychology, 85(3), 361.

Goleman, D. (1995). Emotional Intelligence. New York: Bantam Books.

Goleman, D. (1998). Working with emotional intelligence. New York: Bantam Books.

Goleman, D. (Ed.). (2001). Emotional intelligence: Perspectives on theory of performance. San Francisco: Jossey-Bass.

Harmon, P. (2000). Emotional intelligence: Another management fad, or skill of leverage? Center for Quality of Management Journal, 9(1), 43-51.

Henry, S. (2011). EQ and leadership in Asia: Using emotional intelligence to lead and inspire your people. San Francisco, CA: John Wiley \& Sons.

Herzberg, F. (1966). Work and the nature of man. New York: Thomas Y. Crowell Co.

Higgs, M., \& Dulewicz, V. (1999). Making sense of emotional intelligence. Nfer-Nelson Publishing.

Hong, Y., Catano, V. M., \& Liao, H. (2011). Leader emergence: the role of emotional intelligence and motivation to lead. Leadership \& Organization Development Journal, 32(4), 320-343. http://dx.doi.org/10.1108/0143 7731111134625

Howells, G. N. (2007). Emotional Intelligence and Leadership. Department of Psychology, University of the Pacific. California.

Isen, A. M., \& Reeve, J. (2005). The Influence of Positive Affect on Intrinsic and Extrinsic Motivation: Facilitating Enjoyment of Play, Responsible Work Behavior, and Self-Control. Motivation \& Emotion, 29(4), 295-325. http://dx.doi.org/10.1007/s11031-006-9019-8

Jonker, C. S. (2009). The effect of an emotional intelligence development programme on accountants. $S A$ Journal of Human Resource Management, 7(1), 157-165.

Leban, W., \& Zulauf, C. (2004). Linking emotional intelligence abilities and transformational leadership styles. Leadership \& Organization Development Journal, 25(7), 554-564.

Leonard, N. H., Beauvais, L. L., \& Scholl, R. W. (1999). Work motivation: The incorporation of self-concept-based processes. Human Relations, 52(8), 969-998. http://dx.doi.org/10.1177/001872679 905200801

Lord, R. G., \& Brown, D. J. (2001). Leadership, values, and subordinate self-concepts. Leadership Quarterly, $12(2), 133-152$

Maslow, A. H. (1954). Motivation and personality. New York: Harper \& Row.

Maslow, A. H. (1987). Motivation and Personality (3rd ed.). NY: Harper Collins.

Mayer, J. D., Salovey, P., \& Caruso, D. R. (2000). Models of emotional intelligence. In R. Sternberg (Ed.), Handbook of Intelligence (2nd ed., pp. 396-420). New York: Cambridge University Press.

McClelland, D. C. (1961). The Achieving Society. Princeton, NJ: Van Nostrand.

McClelland, D. C. (1987). Human motivation. Cambridge University Press.

McClelland, D. C. (1998). Identifying competencies with behavioral-event interviews. Psychological Science, 9(5), 331-339.

McEnrue, M. P., Groves, K., \& Shen, W. (2010). Emotional intelligence training: Evidence regarding its efficacy for developing leaders. Leadership Review, 10, 3-26.

McMullen, B. (2003). Emotional intelligence. Research Library, 11, 18-20. 
Novarina, \& Unaradjan, D. (2006). Hubungan antara kecerdasan emosional dengan motivasi kerja di P.T. Timur Jaya Prestasi. Unika Atma Jaya, Jakarta.

Ohtani, K., \& Nakaya, M. (2011). Academic Contingency of Self-worth and Intrinsic Motivation in Academic Failure: Undermining and Enhancing Processes for Intrinsic Motivation and the Mediating Role of State Self-esteem and Emotions. (English). Japanese Journal of Personality, 19(3), 206-216.

Park, S. M., \& Word, J. (2012). Driven to Service: Intrinsic and Extrinsic Motivation for Public and Nonprofit Managers. Public Personnel Management, 41(4), 705-734.

Reeve, J. (2014). Understanding Motivation and Emotion (6th ed.). Wiley.

Reimers, J. M., \& Barbuto, J. E. Jr. (2002). A framework exploring the effects of the Machiavellian disposition on the relationship between motivation and influence tactics. Journal of Leadership \& Organizational Studies, 9(2), 29-41. http://dx.doi.org/10.1177/107179190200900203

Russell, I. L. (1971). Motivation. Dubuque, IA: Wm. C. Brown Company.

Ryan, R. M., \& Deci, E. L. (2000). Intrinsic and extrinsic motivations: Classic definitions and new directions. Contemporary educational psychology, 25(1), 54-67.

Saad, K. (2011). Emotionally smart makes you more motivated: Associations between emotional intelligence, motivation, and work outcomes in police source handlers. University of Ottawa (Canada), ProQuest Dissertations and Theses. Retrieved from https://vpn.utm.my/docview/1366372712?accountid=41678. (NR98330)

Sloman, A. (1987). Motives, mechanisms, and emotions. Cognition and Emotion, 1(3), 217-233.

Steers, R. M., Mowday, R. T., \& Shapiro, D. L. (2004). Introduction to special topic forum: The future of work motivation theory. The Academy of Management Review, 29(3), 379-387.

Sutin, A. R., \& Robins, R. W. (2005). Continuity and Correlates of Emotions and Motives in Self-Defining Memories. Journal of Personality, 73(3), 793-824. doi: 10.1111/j.1467-6494.2005.00329.x

Yusof, H. M., Kadir, H. A., \& Mahfar, M. (2014). The Role of Emotions in Leadership. Asian Social Science, $10(10), 41$.

Zurbriggen, E. L., \& Sturman, T. S. (2013). Linking Motives and Emotions: A Test of McClelland's Hypotheses. Personality and Social Psychology Bulletin, 28(4), 521-535. http://dx.doi.org/10.1177/0146167202287009

\section{Copyrights}

Copyright for this article is retained by the author(s), with first publication rights granted to the journal.

This is an open-access article distributed under the terms and conditions of the Creative Commons Attribution license (http://creativecommons.org/licenses/by/3.0/). 